\title{
DIAGNÓSTICO AMBIENTAL DO AFLUENTE DA BACIA HIDROGRÁFICA DO CÓRREGO AMARGOSO, CIDADE DE TACIBA/SP.
}

\section{ENVIRONMENTAL DIAGNOSIS OF THE STREAMWATER BASIN OF THE AMARGOSO STREAM, CITY OF TACIBA / SP.}

\author{
Mariany Kerriany Gonçalves de Souza ${ }^{1}$; Erica Fernando Gomes ${ }^{2}$; Yeda \\ Ruiz Maria ${ }^{3}$, Nelissa Garcia Balarim ${ }^{4}$, Elson Mendonça Felici ${ }^{5}$ \\ ${ }^{1,2}$ Universidade do Oeste Paulista - UNOESTE, Curso de Engenharia Ambiental e \\ Sanitária \\ E-mail: kerriany gon@yahoo.com.br; erica gomesz@hotmail.com; \\ ${ }^{3,4,5}$ Universidade do Oeste Paulista - UNOESTE, Docentes da Faculdade de Engenharia \\ de Presidente Prudente, SP \\ E-mail: nelissa garcia@hotmail.com; yeda@unoeste.br; \\ elsonfelici@gmail.com;
}

RESUMO - O objetivo desse trabalho é realizar um diagnóstico ambiental dos recursos hídricos do município em Taciba, interior do Estado de São Paulo. A área em estudo é o afluente da microbacia do Córrego Amargoso. Esse trabalho se justifica porque essa área está sendo afetada negativamente pelo descarte inadequado de resíduos sólidos, o assoreamento dos rios, e as erosões e compactações do solo. Realizou-se em quatro pontos a análise da qualidade da água do Córrego Amargoso, considerando parâmetros de pH, DQO, turbidez, fósforo, condutividade, salinidade e nitrogênio. Também realizou-se o estudo hidrológico, levantamento de leis ambientais pertinentes e cabíveis ao município, para auxiliar na caracterização dos impactos ambientais nas áreas de preservação permanente da microbacia. As principais ações a serem tomadas são: de controle e prevenção de erosões, propor alternativas de mitigação, soluções para preservação e conservação dos recursos naturais do Córrego.

Palavras-chave: Microbacia; Aspectos e Impactos Ambientais; Planejamento Ambiental.

Recebido em: $27 / 08 / 2018$

Aprovado em: 04/09/2018
ABSTRACT- The objective of this work is to perform an environmental diagnosis of the water resources of the municipality of Taciba, in the interior of the State of São Paulo. The study area is the tributary of the Amargoso stream microbasin. This work is justified because this area is being negatively affected by the inadequate disposal of solid wastes, the silting of the rivers, and the erosions and compacts of the soil. The analysis of the water quality of the Amargoso stream was carried out in four points, considering parameters of $\mathrm{pH}, \mathrm{DQO}$, turbidity, phosphorus, conductivity, salinity and nitrogen. A hydrological study was also carried out, a survey of pertinent environmental laws that could be applied to the municipality, to assist in the characterization of environmental 
impacts in the areas of permanent preservation of the microbasin. The main actions to be taken are: control and prevention of erosion, propose mitigation alternatives, solutions for preservation and conservation of the natural resources of the Stream.

Keywords: Microbacia; Environmental Aspects and Impacts; Environmental planning. 


\section{INTRODUÇÃO}

As bacias hidrográficas são de grande importância em estudos ambientais e consideradas como unidade de pesquisa de diversos assuntos. Isto se deve a relevância de sua dinâmica e a interação dos elementos químicos, físicos e biológicos existentes, que interferem diretamente na sociedade. Entre as cidades e as bacias hidrográficas existe um abrangente conjunto de inter-relações que influenciam, direta ou indiretamente, as condições ambientais e de vida em áreas urbanas.

Segundo Botelho e Silva (2004), a partir do final da década de 1960, a bacia hidrográfica passou a ser reconhecida como unidade espacial de estudos da Geografia Física. Atualmente, ela é incorporada aos estudos não apenas desta ciência, mas também das Ciências Ambientais como um todo, sendo tida como uma célula de análise ambiental, permitindo o conhecimento e avaliação de seus componentes e as interações entre estes (BOTELHO; SILVA, 2004).

Silveira e Bueno (2013), mencionam que o planejamento na unidade espacial de bacias hidrográficas torna possível um estudo da área associados à sustentabilidade, levando em conta questões sociais, econômicas e ambientais, tornando intrínseca a associação da qualidade de vida com o meio ambiente.

O município de Taciba-SP tem uma área de $607,3 \mathrm{~km}^{2}$, localiza-se no oeste do estado de São Paulo e integra a Unidade de Gerenciamento de Recursos Hídricos do Pontal do Paranapanema - UGRHI - 22, mais precisamente sobre as vertentes dos tributários do rio Paranapanema. Segundo dados do censo IBGE (Instituto Brasileiro de Geografia e Estatística), do ano de 2010, a população total do município é de 5.714 habitantes e a população urbana é de 4.852 habitantes. Segundo a CETESB (Companhia Ambiental do Estado de São Paulo), em 2010, era gerado no município de Taciba 1,9 toneladas dia de resíduos sólidos urbanos.
A área de interesse nesse trabalho está situada na zona norte do município de Taciba-SP, e possui várias residências, setores de atividades agrícolas e pastoril, onde foram encontradas minas de água próximo do antigo depósito de rejeitos, conhecido por "lixão". Sendo, portanto, uma região com muitas fontes poluidoras, devido aos seus impactos gerados ao decorrer do tempo. Assim, avaliar tais efeitos é uma forma de buscar melhorias que visem minimizar a degradação ambiental da área, analisando fragilidades, potencialidades e discutindo propostas mitigadoras em um modelo multidisciplinar.

Nesse sentido, o objetivo desse trabalho é estruturar um diagnóstico ambiental do afluente da Microbacia do Córrego Amargoso na cidade de Taciba-SP.

\section{MÉTODO}

O método aplicado possui algumas etapas, tais como: delimitar a extensão da área de estudo; realizar campanhas de campo para colher amostras de água necessárias para executar as análises físicoquímicas de caracterização a qualidade da água do afluente da bacia hidrográfica Córrego do Amargoso comparando os resultados com a Legislação pertinente; e mapear o uso e ocupação do solo da afluente da bacia hidrográfica observando as áreas de preservação permanentes junto ao Código Florestal, Lei 12.651, de 25 de maio de 2012.

\subsection{Caracterização Física da área}

A caracterização física do Afluente da Bacia Hidrográfica Córrego do Amargoso de Taciba - SP contribui para o diagnóstico ambiental da área, fornecendo informações e dados importantes, para possibilitar a compreensão dos processos que acarretam na degradação da área.

Localizado, sobre o Planalto Ocidental Paulista, o relevo é caracterizado por colinas amplas e médias com declividade das encostas normalmente superior a $15 \%$. As altitudes do município variam de $504 \mathrm{~m}$, ao 
norte, 354 ao sul. Geologicamente, no município, ocorrem os Grupos São Bento e Bauru, representados pelos basaltos da Formação Serra Geral e os arenitos da Formação Adamantina, respectivamente (OLIVEIRA; OLIVEIRA; BOIN, 2011).

O clima local é caracterizado por uma estação seca - inverno e outra chuvosa verão, com precipitação média de $1.278 \mathrm{~mm}$ e temperatura média 23,1 으, com clima, segundo Koeppen - Aw e controlado pelas massas de ar Tropicais e Polares, unidade BIVma, definida por Boin (2000). Os solos do município de Taciba são derivados das rochas areníticas do Grupo Bauru, em quase toda a sua extensão, e de rochas básicas do Grupo São Bento (Formação Serra Geral) na porção sul do município (OLIVEIRA; OLIVEIRA; BOIN, 2011).

Levando em conta as propriedades físico-químicas, estas rochas deram origem a cinco grupos de solo que correspondem ao podzolizado (argissolos) Lins e Marília, à terra roxa estruturada, à terra roxa legítima, ao latossolo vermelho escuro e aos solos hidromórficos (C.N.E.P.A, 1960).

A área total da bacia é de 595 ha, sendo que o canal principal, que nasce junto a Rodovia SP-483, percorre 3.365 metros até o "piscinão" e 4.102 metros até sua foz junto ao córrego Formiga (Figura 2). Com relação ao principal ponto de contaminação o trajeto percorrido pela água é de 2.578 metros até o "piscinão" ou balneário da cidade de Taciba. Pela hierarquização proposta por Strahler e Strahler (1994), a bacia do Amargoso é uma bacia de quinta ordem, e tem em seu interior uma grande quantidade de lençóis suspensos, onde parte se localiza em fundos de vale e parte em meia encosta, é comum a presença de bancos Arenosos (psamitos) intercalados com bancos Silto/Argiloso (lamitos) que retarda o fluxo de água vertical, ocasionando assim os lençóis suspensos. Essas características são comuns a Formação Adamantina, e estão presentes na bacia do córrego Amargoso. A avaliação ambiental da interferência de lixões e aterros sanitários no meio físico, assim como todas as avaliações ambientais acerca de qualquer forma de ocupação do solo, necessita inicialmente da identificação dos atributos a serem avaliados (OLIVEIRA; OLIVEIRA; BOIN, 2011).

\subsection{Caracterização da Área de estudo}

Essa etapa foi cumprida mediante estudo da literatura e visitas em campo. Assim, fez-se a caracterização e levantamento prévio da área de estudo, identificando alguns aspectos e impactos ambientais como: erosões, grande movimentação de gado, descarte irregular de construção civil e um lixão inativo.

\subsection{Determinação da Forma da Bacia}

O afluente do presente estudo, representado na ortofoto abaixo (Figura 1), está inserido na microbacia Córrego do Amargoso (Figura 2), onde essa microbacia pertence a bacia hidrográfica Córrego Formiga e suas águas ao adentrarem o córrego Formiga, passam pela cidade de Taciba - SP, localiza-se ao norte do município, através das coordenadas Lat: $22.402578^{\circ} \mathrm{S}$ e Long: $-51.306034^{\circ} \mathrm{W}$.

Figura 1. Ortofoto representado o Afluente do Córrego do Amargoso de Taciba-SP.

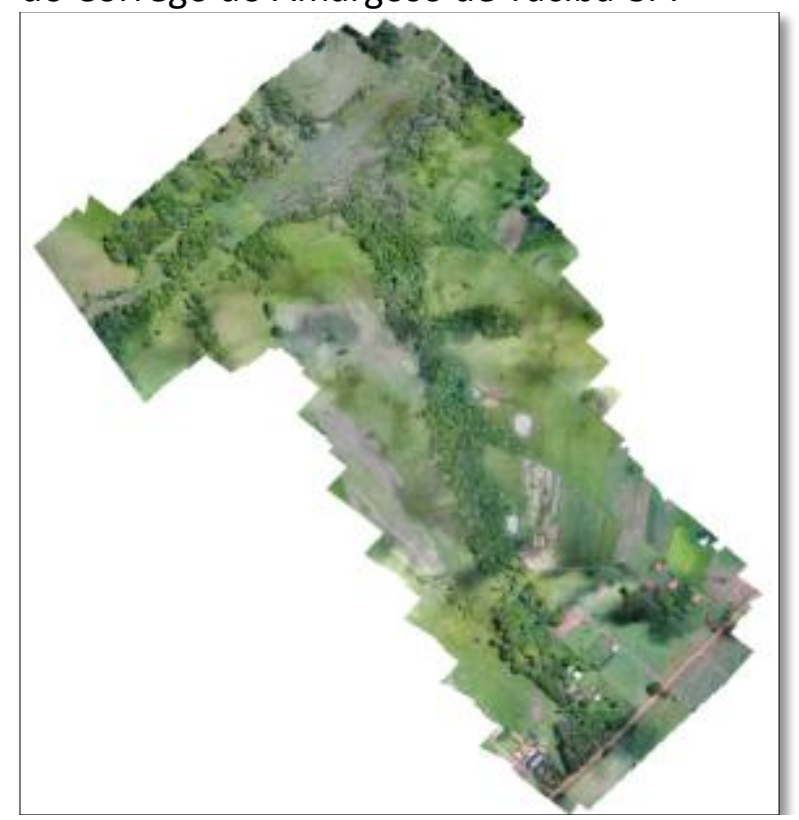

Fonte: Os Autores (2018). 
Figura 2. Bacia delimitada através do SIG QGIS 2.18.

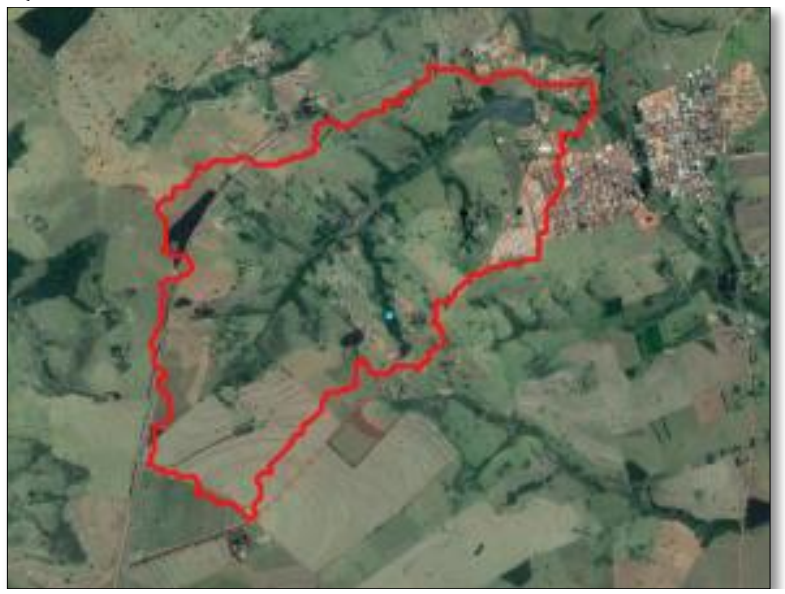

Fonte: Os Autores (2018).

\subsection{Mapa de Uso e Ocupação do Solo}

O mapa de uso e ocupação do solo (Figura 3) apresenta os elementos existentes na microbacia, tais como pequenas agriculturas familiares, pastagem e a área de preservação permanente. A parte do afluente estudado, quase por completo respeita os recuos para APP.

Figura 3. Mapa de Uso e Ocupação do Solo do Córrego do Amargoso.

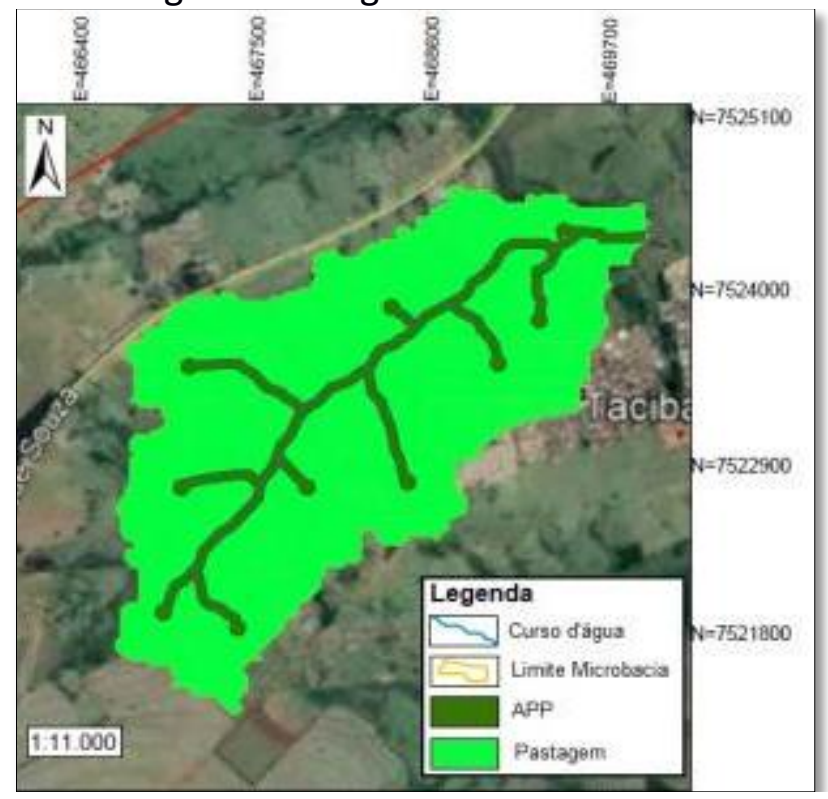

Fonte: Google Earth (2017).

Observa-se que a área em estudo é ocupada em maior parte por pastagens, sendo, portanto, uma região que está em constante crescimento para habitação, o que chama a atenção para as necessidades de preservação, conservação e sua qualidade ambiental.

\subsection{Determinação dos pontos de coleta de amostra da água para análise}

Fez-se a análise de quatro amostras de água ao longo do afluente em estudo, para isso foram determinados quatro pontos de coleta e coletados $1000 \mathrm{ml}$ de água.

A Imagem aérea do afluente do córrego do Amargoso (Figura 4), ilustra os locais onde foram tiradas as fotografias em visitas "in loco" e também para indicar aonde as amostras de água foram coletadas (Figura 4).

Figura 4. Determinação dos quatro pontos de coletas.

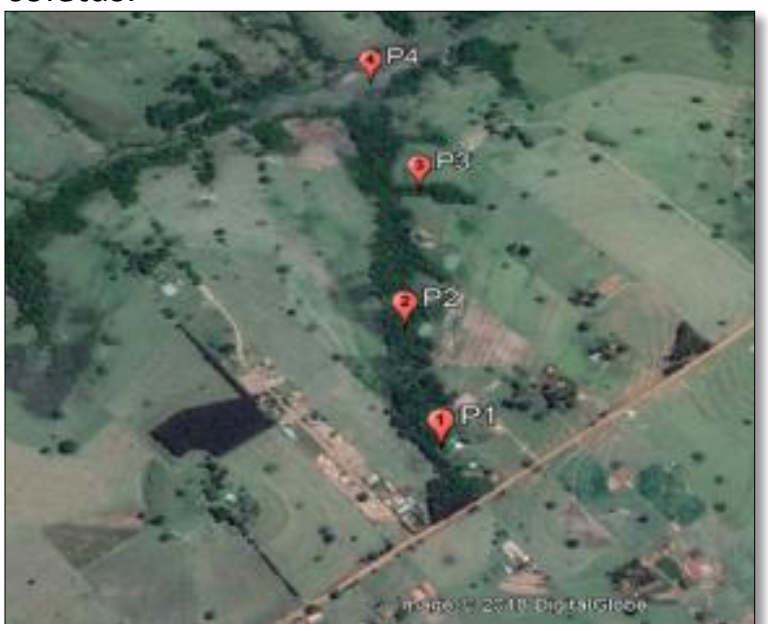

Fonte: Google Earth Pro (2018)

Para as coletas em campos das amostras, foram feitas as revisões bibliográficas para atender os parâmetros adequados, e tomou-se por base as seguintes normas técnicas:

- NBR 9897 - Planejamento de amostragem de efluentes líquidos e corpos receptores - Junho 1987;

- NBR 9898 - Preservação e técnicas de amostragem de efluentes líquidos e corpos receptores - Jun 1987;

O primeiro ponto em estudo é a nascente do afluente (Figura 5), esse ponto foi escolhido para determinar a qualidade da água sem nenhuma interferência dos outros braços do córrego. A coleta foi realizada no dia 01/04/2018 às 08:57 (horário de Brasília) 
nas coordenadas P1 = 22은 O.

Figura 5. Coleta da primeira amostra.

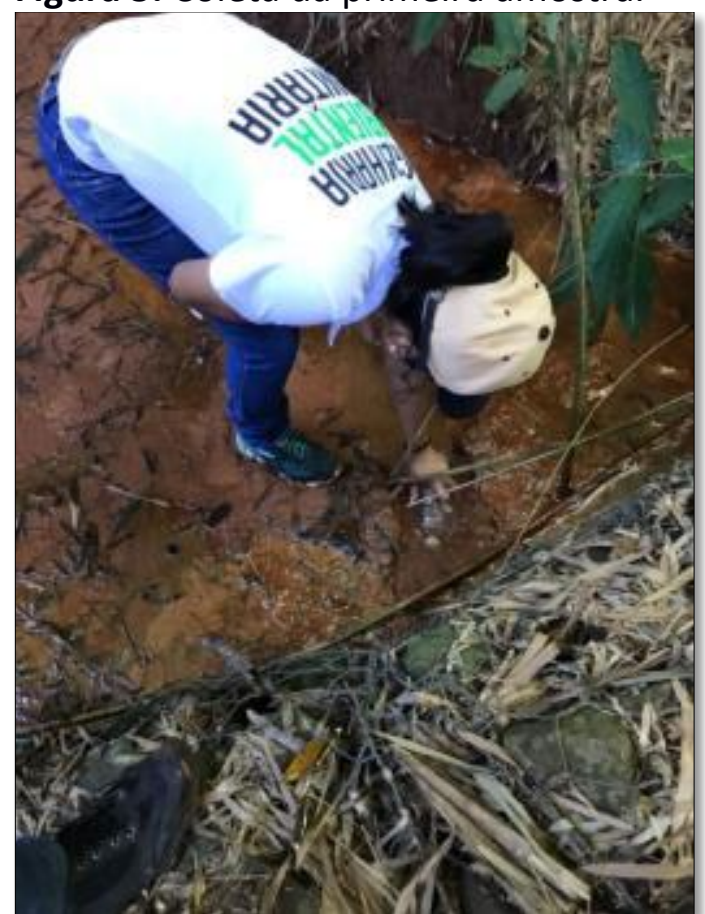

Fonte: Os autores (2018)

O segundo ponto (Figura 6), localizese próximo ao lixão inativo, onde o intuito principal era determinar a qualidade da água do córrego levando em consideração uma possível lixiviação dos poluentes ainda presentes naquela área, o mesmo também está localizado próximo a uma área onde há uma intensa movimentação de gado. A coleta foi realizada no dia $01 / 04 / 2018$ às $09: 28$ (horário de Brasília) nas coordenadas P2 = 2223'57" S 51일'26" O.
Figura 6. Coleta da segunda amostra

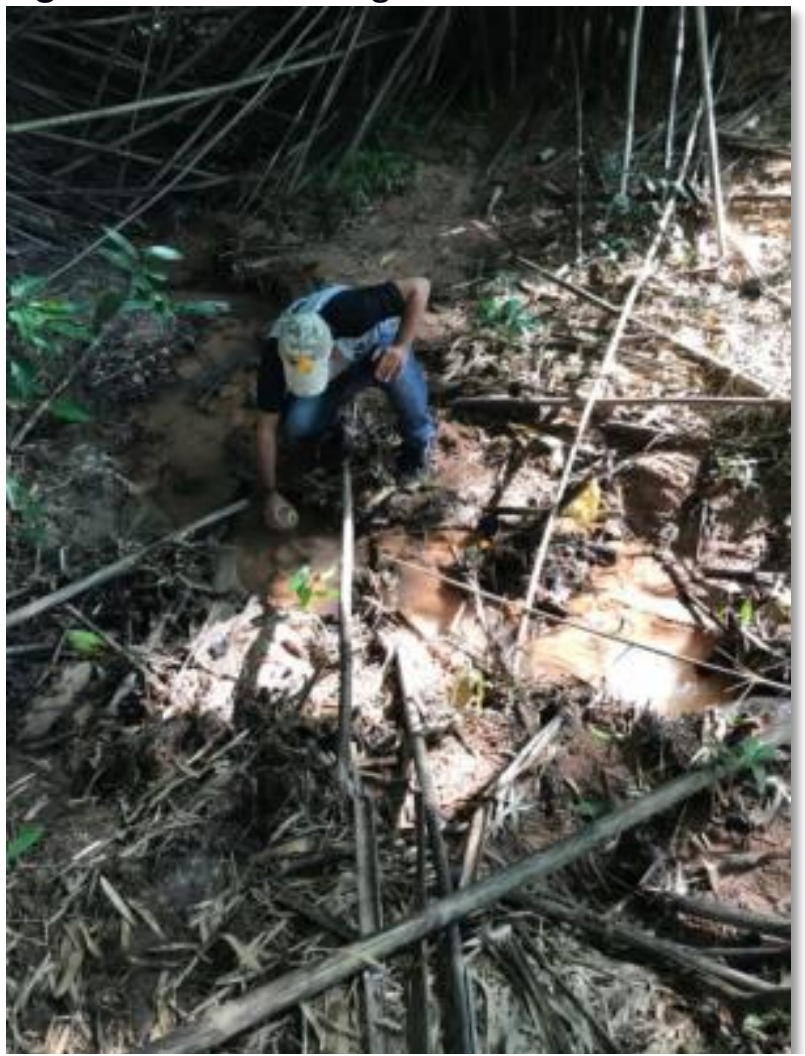

Fonte: Autores (2018)

0 terceiro ponto (Figura 7), caracteriza-se por se localizar próximo a uma nascente onde, teoricamente, não há interferência antrópicas, uma vez levantada que há descarte irregular de construção civil a aproximadamente $300 \mathrm{~m}$ do local coletado. A coleta foi realizada no dia 01/04/2018 às 10:16 (horário de Brasília) nas coordenadas P3 = 2223'47" S 51ำ18'28" O. 
Figura 7. Coleta da terceira amostra.
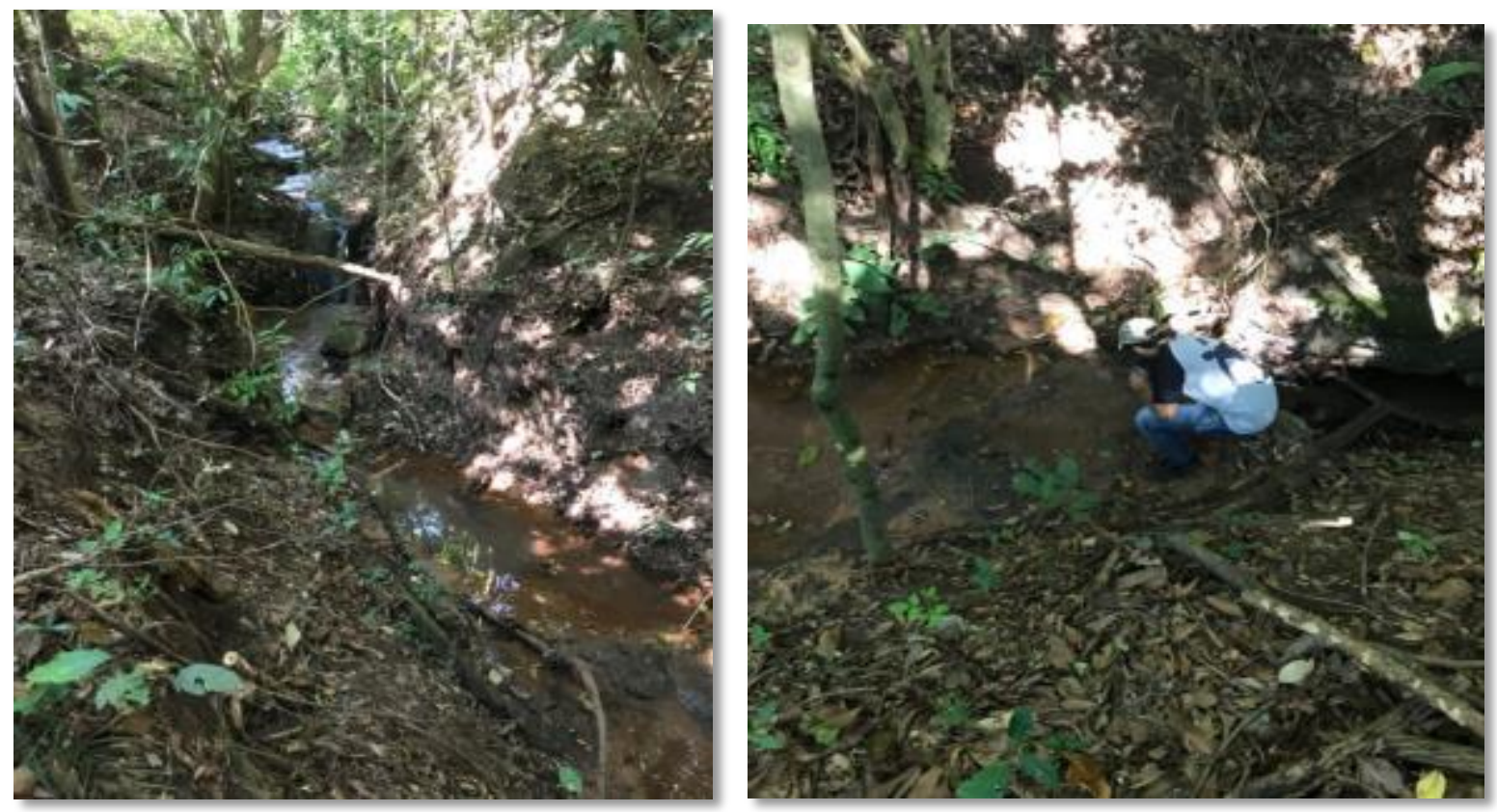

Fonte: Autores (2018).

O quarto e último ponto (Figura 8), é a foz do nosso afluente que está a jusante da nascente, o mesmo foi escolhido para efeito de comparação da qualidade da água entre os outros três pontos anteriores. $(\mathrm{P} 4=$ 2223'38" S 511'ㄱ' O). A coleta foi realizada no dia 01/04/2018 às 10:32 (horário de Brasília) nas coordenadas citadas acima.

Figura 8. Coleta da 4a amostra, foz do afluente.
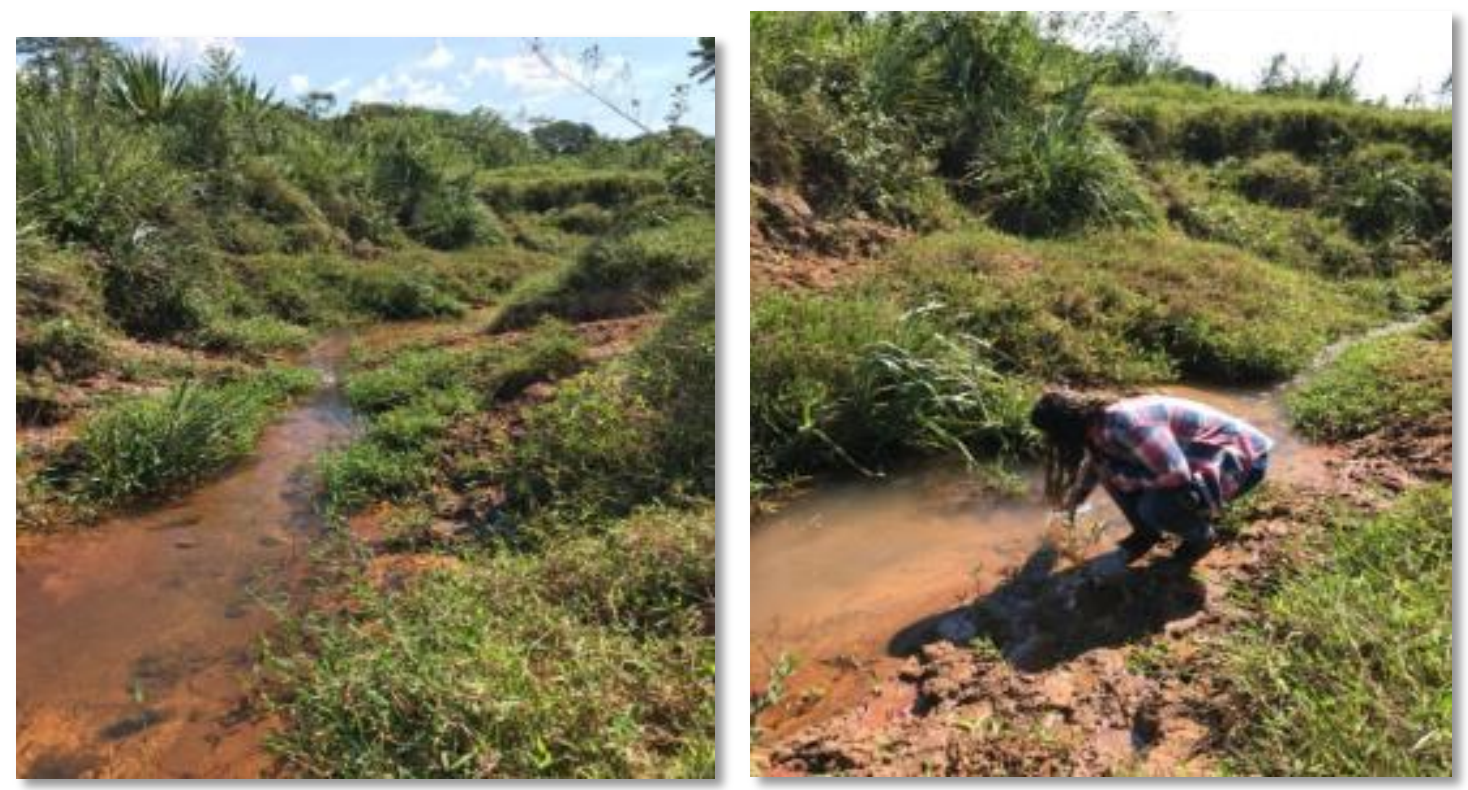

Fonte: Autores (2018). 
Figura 9. Amostras coletadas.

Fonte: Autores, 2018.

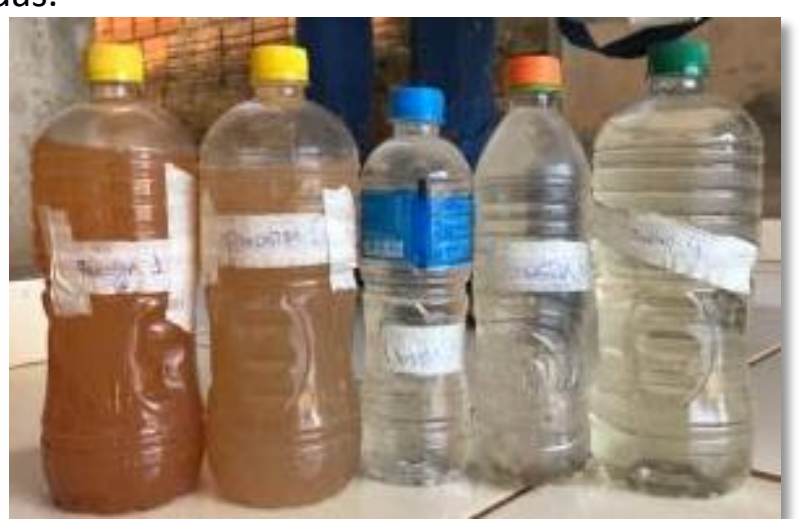

\section{RESULTADOS E DISCUSSÕES}

Utilizando a metodologia apresentada, foi realizado a interpretação dos resultados sendo possível justificá-los, ou apresentar possíveis justificativas para os mesmos, considerando toda a atividade natural e antrópica identificada na área.

\subsection{Levantamento dos Aspectos/Impactos relacionados a área de estudo.}

No estudo do afluente da microbacia Córrego do Amargoso em Taciba - SP é essencial identificar os aspectos e impactos ambientais para se realizar um diagnóstico ambiental. Para identificá-los foi necessário analisar todas as atividades antrópicas, para depois avaliar cada um dos impactos gerados. Essas informações possibilitam auxiliar na adoção de medidas para amenizar e evitar que esses impactos se agravem, valorizando-se assim os corpos hídricos da área.

A partir das visitas em campo foi possível identificar os problemas no local com o auxílio de fotos dos locais apresentando tais interferências mostra os pontos em que foram observados os impactos ambientais

Assim foram encontrados alguns entulhos de construções civis e também a disposição inadequada de resíduos sólidos, observada na área (Figura 10 e 11).
Figura 10. Entulhos de construções civis.

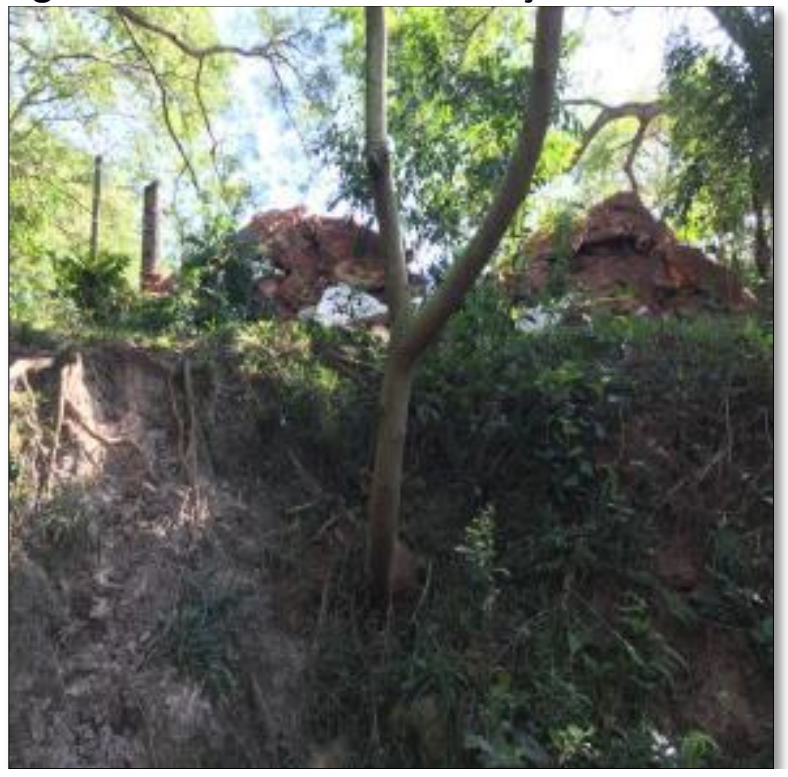

Fonte: Autores (2018).

Figura 11. Entulhos de construções civis.

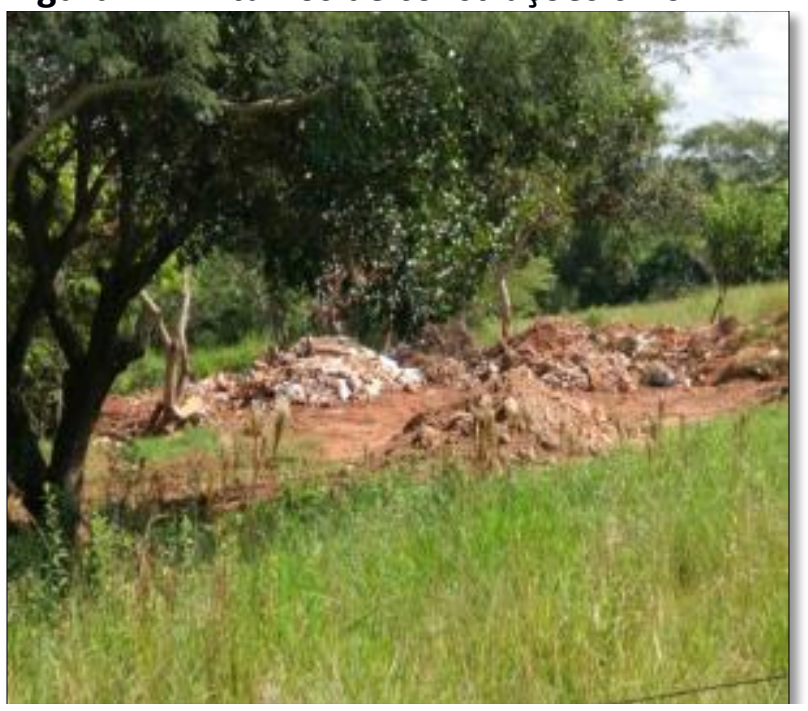

Fonte: Autores (2018). 
Por ser uma área que está em expansão, à região em torno do afluente e da microbacia Córrego do Amargoso sofre ações antrópicas como a compactação do solo devido ao pisoteio do gado (Figura 12 a e b); erosões (Figura 13 a e b); assoreamento do córrego (Figura 14) e cortes de árvores (Figura 15).

Figura 12. Compactação do solo devido ao pisoteio do gado.

(a)

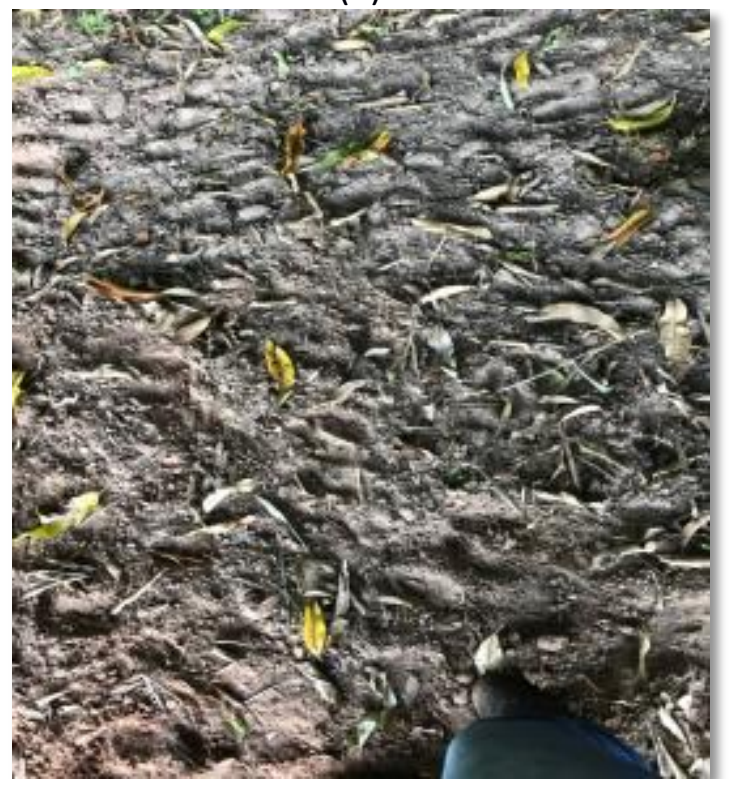

(b)

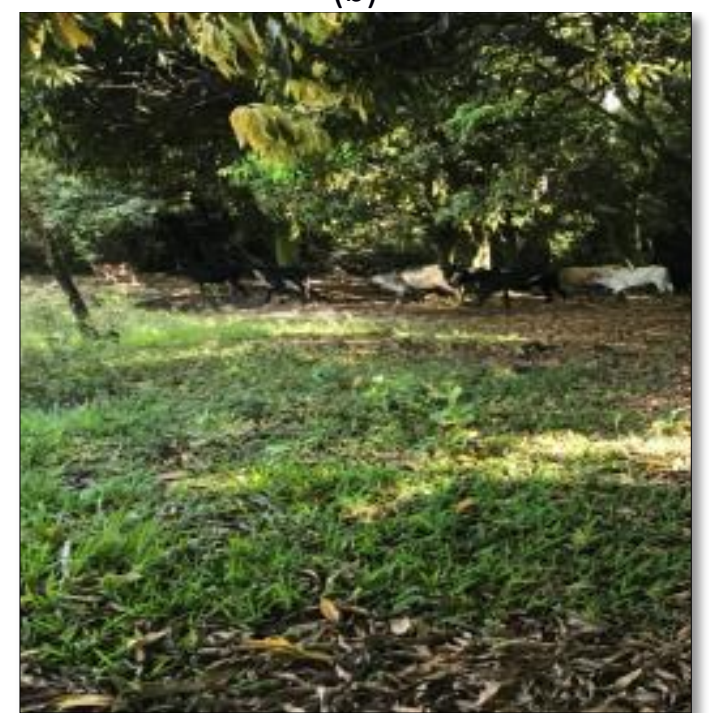

Fonte: Autores (2018).
Figura 13. Erosões observadas na área.

(a)

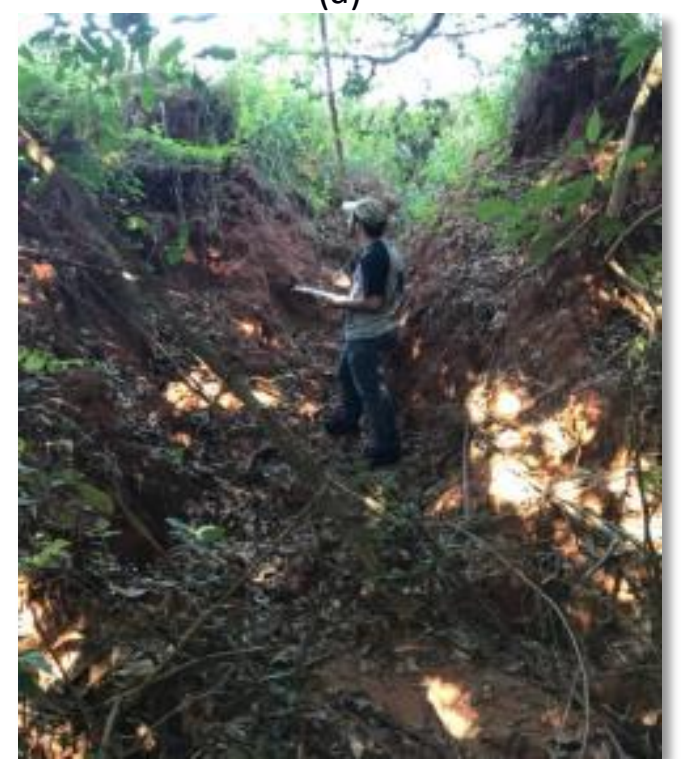

(b)

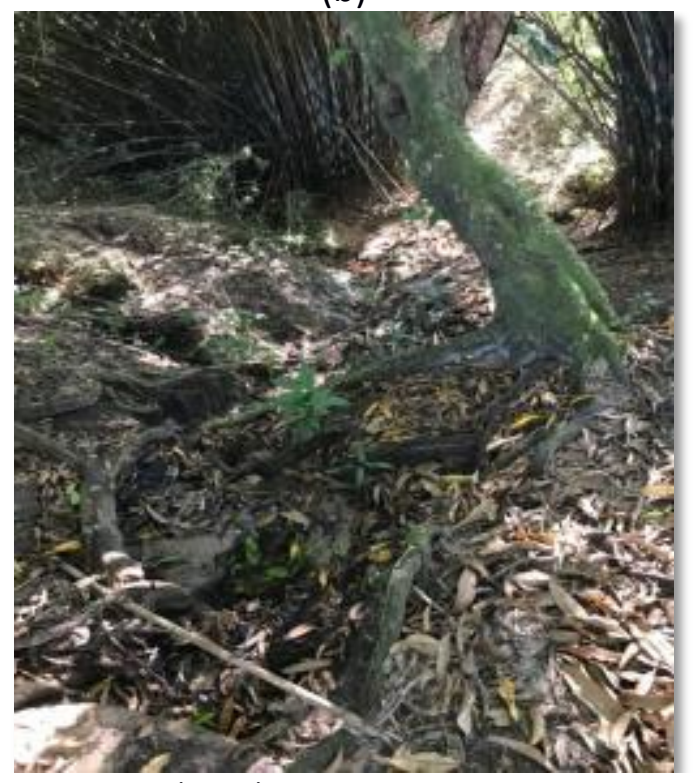

Fonte: Autores (2018). 
Figura 14. Assoreamento do Córrego Amargoso.

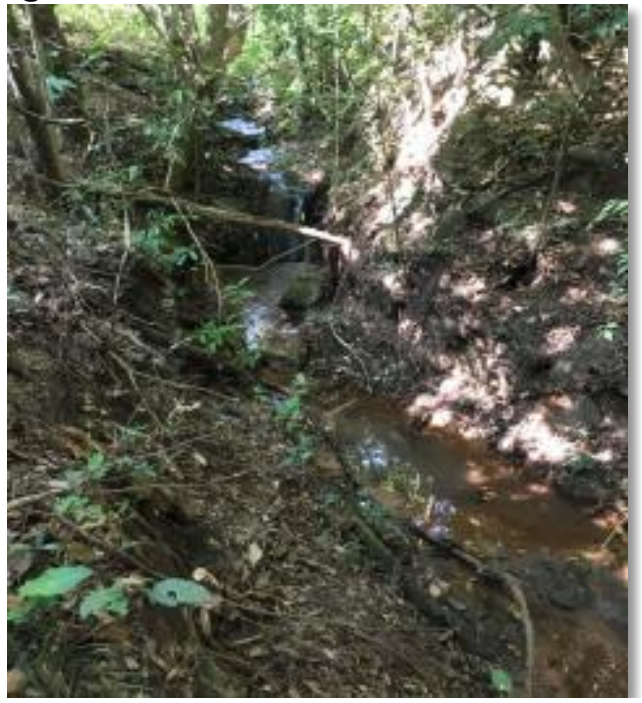

Fonte: Autores (2018).

Figura 15. Cortes de árvores.

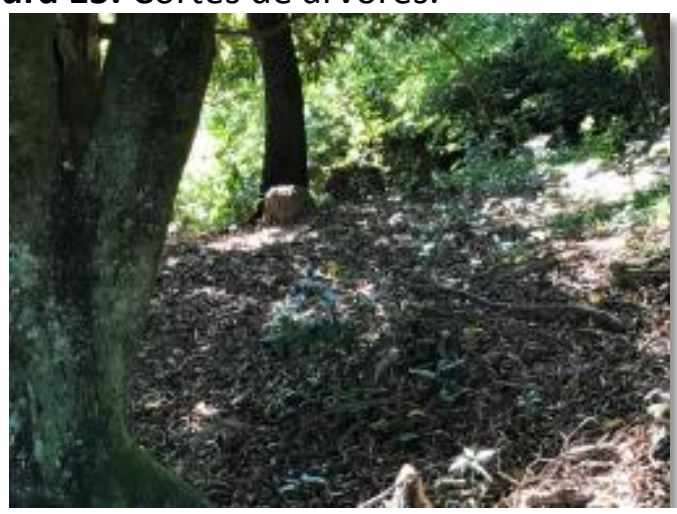

Fonte: Autores (2018).

Através das visitas in loco foi possível observas, que algumas regiões perto do córrego estão sem cobertura vegetal. Esses fatores contribuem para a degradação do curso d'água, o que torna necessária a adoção de ações voltadas a sua recuperação, evitando assim que os impactos se intensifiquem ao longo do tempo.

\subsection{Análise de Potabilidade.}

Procedimento laboratorial, no qual foram analisados, o parâmetros analisado, equipamentos e métodos da bibliografia Standard Methods for the Examination of Water and Wastewater da água coletada no afluente Córrego do Amargoso, a fim de diagnosticar os componentes da mesma, e comparar com os valores prescritos pelo Decreto Estadual no 10.755/1977 e pelos padrões permitidos pela Resolução CONAMA n. 357/05 para corpos de águas, no qual seu resultado, dirá ou não ser a lei está sendo cumprida no mesmo. Os parâmetros analisados foram (Tabela 1).

Tabela 1. Parâmetros analisados na qualidade da água.

\begin{tabular}{|c|c|c|}
\hline PARÂMETRO & MÉTODO & REFERÊNCIA \\
\hline PH & Potenciométrico & $\begin{array}{c}\text { SMWW - 4500 } \\
- \text { H+2 }\end{array}$ \\
\hline Temperatura & $\begin{array}{c}\text { Termômetro de } \\
\text { Mercúrio }\end{array}$ & $\begin{array}{c}\text { SMWW - 2550 } \\
- \text { B }\end{array}$ \\
\hline Turbidez & Método de \\
& Turbidimetro & SMWW - 2130 \\
B
\end{tabular}

\subsection{1- Parâmetros Físicos e Químicos de} Qualidade da Água

As referências de práticas laboratoriais foram todas através da metodologia do Standard Methods for the Examination of Water and Wastewater para analisar cada um desses parâmetros. A Resolução CONAMA n. 357/05 para corpos de águas doces classe 2, define que: $\mathrm{Ph}$ : índice de $\mathrm{pH}$ deve estar na faixa de 6 a 9; Turbidez: os resultados estão dentro dos padrões permitidos de limite máximo de 100 UNT; DQO: valores para este parâmetro são no mínimo até $0,009 \mathrm{mg} / \mathrm{L}$; Fósforo: valor máximo permitido é $0,050 \mathrm{mg} / \mathrm{L}$.

Os resultados dos parâmetros analisados estão apresentados na Tabela 2: 
Tabela 2. Resultados dos parâmetros analisados na qualidade da água.

\begin{tabular}{|c|c|c|c|c|c|c|c|}
\hline Pontos & pH & $\begin{array}{c}\text { Condutividade } \\
\text { (uS/cm }\end{array}$ & $\begin{array}{c}\text { Salinidade } \\
\text { (\%) }\end{array}$ & $\begin{array}{c}\text { Turbidez } \\
\text { (UNT) }\end{array}$ & $\begin{array}{c}\text { DQO } \\
\text { (mg/L) }\end{array}$ & $\begin{array}{c}\text { Fósforo } \\
\text { (mg/L) }\end{array}$ & $\begin{array}{c}\text { Nitrogênio } \\
\text { (mg/L) }\end{array}$ \\
\hline P1 & 6,9 (ácido) & 444 & 20 & 454 & 0,06 & 0,065 & 0,1242 \\
\hline P2 & $\begin{array}{c}6,72 \\
\text { (ácido) }\end{array}$ & 107 & 6 & 279 & 0,003 & 0,06 & 0,362 \\
\hline P3 & $\begin{array}{c}6,19 \\
\text { (ácido) }\end{array}$ & 85 & 3 & 18,3 & 0 & 0,003 & 0,025 \\
\hline P4 & $\begin{array}{c}6,35 \\
\text { (ácido) }\end{array}$ & 46 & 1 & 13 & 0,009 & 0,011 & 0,74 \\
\hline
\end{tabular}

\subsection{Analise de Impactos Ambientais.}

O conceito de avaliação dos impactos ambientais nada mais é que uma breve descrição e caracterização das atividades potencialmente modificadoras no meio ambiente. Partindo desse pressuposto, o grupo se apresentou duas vezes em campo para a identificação dos impactos ambientais na área de estudo, com isso foi elaborado uma tabela organizando "Aspectos" e "Impactos" (Quadro 1):

Quadro 1. Aspectos X Impactos.

\begin{tabular}{|l|l|}
\hline \multicolumn{1}{|c|}{ ASPECTOS } & \multicolumn{1}{|c|}{ IMPACTOS } \\
\hline Erosões & $\begin{array}{l}\text { Perda de nutrientes } \\
\text { Remoção da camada superficial } \\
\text { Assoreamento }\end{array}$ \\
\hline $\begin{array}{ll}\text { Descarte irregular de } \\
\text { resíduos sólidos de } \\
\text { construção Civil }\end{array}$ & $\begin{array}{l}\text { Poluição/Contaminação do Solo } \\
\text { Poluição/Contaminação dos } \\
\text { Recursos hídricos }\end{array}$ \\
\hline & de \\
\hline Movimentação & $\begin{array}{l}\text { Compactação do solo } \\
\text { Eutrofização } \\
\text { Susceptibilidade a processos } \\
\text { erosivos }\end{array}$ \\
\hline & Lixão inativo \\
& $\begin{array}{l}\text { Vestígios de contaminantes no } \\
\text { solo } \\
\text { Perda de nutrientes no solo } \\
\text { Perda de área cultivável }\end{array}$ \\
\hline
\end{tabular}

Fonte: Autores (2018)

Realizado o diagnóstico ambiental da área de estudo, pesquisamos sobre medidas mitigadoras para impacto ambiental citado, visando obter respostas e propondo possíveis sugestões para sanear tal impacto.
3.4. Medidas de Mitigação e Compensação dos impactos ambientais

Definimos medidas de mitigação o conjunto de ações que serão realizadas para reduzir os impactos ambientais negativos no 
meio de estudo. Tais medidas tratam de antever, evitar e reduzir os impactos que foram levantados anteriormente.

Para o presente estudo, foram elaboradas propostas preventivas e compensatórias para a recuperação dos impactos ambientais levantados. As informações foram reunidas em uma tabela onde estão listados os "Impactos, Medidas de mitigação e Medidas compensação" (Quadro 2).

Quadro 2 - Medidas de Mitigação e Compensação.

\begin{tabular}{|c|c|c|}
\hline IMPACTO & $\begin{array}{c}\text { MEDIDAS } \\
\text { PREVENTIVAS }\end{array}$ & $\begin{array}{c}\text { MEDIDAS } \\
\text { COMPENSATÓRIAS }\end{array}$ \\
\hline Erosões & $\begin{array}{l}\text { Cobertura } \\
\text { das áreas; } \\
\text { Criação de } \\
\text { de nível; } \\
\text { Rotação } \\
\text { cultura. }\end{array}$ & $\begin{array}{l}\text { Revegetação } \\
\text { recomposição das áreas } \\
\text { erodidas; } \\
\text { Técnicas } \\
\text { bioengenharia. }\end{array}$ \\
\hline $\begin{array}{lr}\text { Descarte } & \text { Irregular } \\
\text { de } & \text { Resíduos } \\
\text { Sólidos } & \text { de } \\
\text { construção civil }\end{array}$ & $\begin{array}{lr}\begin{array}{l}\text { Deposição } \\
\text { dos correta }\end{array} & \text { resíduos, } \\
\text { segundo } & \text { a } \\
\text { Resolução } & \\
\text { CONAMA } & n^{\circ} \\
307 / 2002 & \end{array}$ & $\begin{array}{l}\text { Retirar os resíduos do } \\
\text { local e transportá-los, } \\
\text { segundo a Resolução } \\
\text { CONAMA n }{ }^{\circ} 307 / 2002\end{array}$ \\
\hline $\begin{array}{l}\text { Movimentação de } \\
\text { gados (Pisoteio) }\end{array}$ & $\begin{array}{l}\text { Cercamento da } \\
\text { área onde há } \\
\text { movimentação dos } \\
\text { animais de grande } \\
\text { porte; } \\
\text { Criação de uma } \\
\text { ponte interligando } \\
\text { os dois lados do } \\
\text { solo }\end{array}$ & $\begin{array}{l}\text { Aplicação das medidas } \\
\text { preventivas; } \\
\text { Desassoreamento dos } \\
\text { pequenos cursos d'aguas } \\
\text { onde há a } \\
\text { movimentação intensa } \\
\text { do gado; } \\
\text { Descompactação do solo } \\
\text { inserindo cobertura do } \\
\text { mesmo. }\end{array}$ \\
\hline Lixão inativo & $\begin{array}{l}\text { Substituição por } \\
\text { um aterro } \\
\text { sanitário; }\end{array}$ & $\begin{array}{l}\text { Controle dos níveis de } \\
\text { poluentes presente no } \\
\text { solo; } \\
\text { Preservação da área; } \\
\text { Impedir o depósito de } \\
\text { qualquer tipo de } \\
\text { resíduo. }\end{array}$ \\
\hline
\end{tabular}

\section{CONSIDERAÇÕES FINAIS}

O Município deveria adotar medidas mitigadoras e compensatória para a microbacia Córrego do Amargoso, tais como uso de tecnologias mais limpas, segregação e destinação adequada de resíduos, controle de erosões, fiscalização mais exigente do poder público. Tais ações que podem favorecer a recuperação e conservação desses recursos naturais e ambientais, trazendo bem-estar social e econômico para todos.

\section{AGRADECIMENTOS}

A estrutura fornecida pela Unoeste para o desenvolvimento do presente trabalho. 


\section{REFERÊNCIAS}

ABNT. NBR 9897. Planejamento de amostragem de efluentes líquidos e corpos receptores. Rio de Janeiro: ABNT, 1987.

ABNT. NBR 9898. Preservação e técnicas de amostragem de efluentes líquidos e corpos receptores. Rio de Janeiro: ABNT, 1987.

APHA Standard Methods for the examination of water and Wasterwater. American Public Health Association, American Water Works Association, Water Environmental Federation $20^{\text {th }}$ ed. Washigton: APHA, 1998.

BOIN, M. N. Chuvas e erosões no oeste paulista: uma análise climatológica aplicada. 2000. 264f. Tese (Doutorado em Geociências) - I. G. C. E. UNESP, Rio Claro, 2000.

BOTELHO, R. G. M.; SILVA, A.S. Bacia hidrográfica e qualidade ambiental. In: VITTE, A. C.; GUERRA, A. J. T. (org.). Reflexões sobre a Geografia Física no Brasil. Rio de Janeiro: Berthand Brasil, 2004.p.153-192.

BRASIL. Conselho Nacional do Meio Ambiente. Resolução no $\mathbf{3 5 7}$ de $\mathbf{1 7}$ de março de 2005. Disponível em: http://www.mma.gov.br/port/conama/legia bre.cfm?codlegi=459. Acesso em: 22 maio 2018.

CETESB. Qualidade das águas interiores no estado de São Paulo. Companhia de Tecnologia de Saneamento Ambiental. São Paulo, 2009.

BRASIL. LEI № 12.651, de 25 de maio de 2012. Dispõe sobre a proteção da vegetação nativa e dá outras providências. Presidência da República. Casa Civil. Subchefia para Assuntos Jurídicos. Brasília, 2012.

C.N.E.P.A. (Comissão de Solos) Levantamento de reconhecimento dos solos do estado de São Paulo. Boletim do Serviço Nacional de
Pesquisas Agronômicas, Rio de Janeiro, v.12, 634p, 1960

OLIVEIRA, R. C; OLIVEIRA, M. H; BOIN, M. N. Disposição Inadequada de Resíduos Sólidos Domésticos no Município de Taciba - SP. 2011. 198f. - FACLEPP - UNOESTE. Presidente Prudente - SP.

OLIVEIRA, M. H., Avaliação da qualidade das águas superficiais da microbacia do córrego do Amargoso Taciba (SP). 2002. 88f. Tese (Doutorado em Geografia). F. C. T. UNESP. Presidente Prudente-SP, 2002.

Resolução nº 307 (2002). Diretrizes, critérios e procedimentos para a gestão dos resíduos da construção civil. Conselho Nacional do Meio Ambiente (CONAMA). Brasília.

SÃO PAULO. Assembleia Legislativa. Decreto no 10.755/1977. Dispõe sobre o enquadramento dos corpos de água receptores na classificação prevista no Decreto no 8.468 , de 8 de setembro de 1976, e dá providências correlatas. Diário Oficial do Estado de São Paulo, São Paulo, SP, 22 nov. 1977. Disponível em: < http://www.sigrh.sp.gov.br/arquivos/enquad ramento/Dec_Est_10755.pdf>.

SILVEIRA, A. F.; BUENO, L. M. M. Sustentabilidade e vivências em uma Bacia Hidrográfica Urbana: Resultados de Intervenções Recentes. Campinas/SP, Brasil. In: ENCUENTRO DE GEÓGRAFOS DE AMÉRICA LATINA, 14., 2013, Perú. Anais [...]. Lima, Perú, 2013. p. 1-18.

STRAHLER, A.N.; STRAHLER, A. H. Geografia física. 3. ed. Barcelona: E Ômega, 1994. 